\title{
Problem Kompatibilitas dan Stabilitas Pencampuran Sediaan Intravena Pada Pasien Anak di RSUP Dr. Sardjito
}

\section{Intravenous Drug Compatibility and Stability Problem in Pediatric Patient at RSUP Dr. Sardjito}

\author{
Reza Rahmawati ${ }^{1}$, Fita Rahmawati ${ }^{2}$, Syed Azhar Syed Sulaiman ${ }^{3}$ \\ rezarahma10@gmail.com \\ ${ }^{1}$ Magister Farmasi Klinik, Fakultas Farmasi, Universitas Gadjah Mada, Yogyakarta, Indonesia \\ ${ }^{2}$ Fakultas Farmasi, Universitas Gadjah Mada, Yogyakarta, Indonesia \\ ${ }^{3}$ School of Pharmaceutical Sciences, Universiti Sains Malaysia, Pulau Pinang, Malaysia
}

\begin{abstract}
Abstrak
Penyiapan dan pemberian obat intravena yang tidak tepat dapat membahayakan dan menyebabkan kegagalan terapi pada pasien. Pada pasien anak, pemberian obat intravena sangat kritis karena keterbatasan pembuluh vena terutama ketika dilakukan pemberian obat secara bersamaan dalam satu waktu yang dapat memicu terjadinya inkompatibilitas. Kesalahan dalam pencampuran obat intravena juga dapat mempengaruhi stabilitas obat. Oleh karena itu, penelitian ini dilakukan untuk mengetahui prevalensi kejadian inkompatibilitas dan stabilitas obat intravena pada pasien rawat inap anak. Pengambilan data dilakukan secara prospektif di RSUP Dr. Sardjito di ruang rawat inap intensif anak (PICU) dan bangsal anak dari November-Desember 2017. Pengambilan data dilakukan pada pasien rawat inap anak yang menggunakan minimal 1 obat intravena dan dilakukan analisis kompatibilitas dan stabilitas obat menggunakan referensi standar Handbook of Injectable Drugs dan referensi lain. Jumlah pasien yang memenuhi kriteria inklusi adalah 75 pasien, dimana 34 pasien dari PICU dan 41 pasien dari bangsal anak. Pemberian obat melalui rute intravena sebanyak $49.1 \%$ dengan rata-rata penggunaan obat intravena 3.3 obat/pasien. Pasangan obat yang kompatibel adalah sebanyak $73.7 \%$ dan unknown sebanyak $26.3 \%$. Tidak ditemukan adanya pasangan obat yang inkompatibel dalam penelitian ini. Permasalahan stabilitas yang terjadi pada pemberian infus continue pada 3 pasangan obat apabila digunakan lebih dari waktu yang tertera pada literatur.
\end{abstract}

Kata kunci : pemberian intravena, kompatibilitas, stabilitas, pasien anak.

\begin{abstract}
Inappropriate preparation and administration intravenous drug may caused harm and therapeutic failure for the patient. In pediatric patient, intravenous drug administration is very critical because of poor venous access especially when simultaneously drug administration required which is can lead into incompatibilities occurence. Errors in intravenous drug administration can affect the drug stability also. Therefore, this research aims to investigate the prevalence of incompatibility and stability in pediatric hospitalized patient. This research was done with prospective study at RSUP Dr. Sardjito in
\end{abstract}


Pediatric Intensive Care Unit (PICU) and pediatric ward from NovemberDecember 2017. Data collection was done with pediatric hospitalized patient that used at least 1 intravenous drug. Compatibility and stability were analyzed using standard reference Handbook of Injectable Drugs and other references. A total pediatric hospitalized patients are 75 patients, 34 patients are from PICU and 41 patients are from pediatric ward. Intravenous drugs used are $49.1 \%$ with the mean of intravenous drugs are 3.3 drugs/patient. Compatible drug combinations are $73.3 \%$ and unknown are $26.3 \%$. There are no incompatible drug combination found in this research. Stability problems were found in 3 drug combination that administered by continuous infusion.

Keywords: intravenous administration, compatibility, stability, pediatric

\section{Pendahuluan}

Penggunaan obat intravena di rumah sakit semakin meningkat terutama pasien di ruang rawat intensif yang memerlukan efek farmakologi obat yang cepat dan dalam keadaan tidak sadarkan diri. Penyiapan dan pemberian obat intravena cukup kompleks. Penyiapan dan pemberian obat intravena yang tidak tepat dapat membahayakan pasien karena obat langsung masuk ke dalam pembuluh darah. Pemberian obat intravena dapat menyebabkan inkompatibilitas, emboli, plebitis, infiltrasi dan ekstravasasi. Penelitan sebelumnya melaporkan bahwa permasalahan dalam pemberian obat intravena adalah inkompatibilitas (Vijayakumar dkk., 2014).

Resiko pemberian obat intravena pada pasien anak lebih tinggi dibandingkan pada pasien dewasa. Resiko akibat medication error pada anak meningkat sebanyak 3 kali lipat dibandingkan pasien dewasa. Pemberian obat intravena juga merupakan salah satu penyebab potensi kejadian obat yang tidak diharapkan/Adverse Drug Events (ADEs) (Kaushal dkk., 2001). Pasien yang dirawat di Intensive Care Unit (ICU) adalah pasien dengan resiko tinggi mengalami kejadian inkompatibilitas obat (Marsilio dkk., 2016).

Inkompatibilitas terjadi apabila 2 atau lebih obat diberikan pada jalur intravena yang sama atau dicampur pada satu wadah yang sama dan menghasilkan reaksi yang tidak diinginkan. Inkompatibilitas terbagi menjadi 3 yaitu fisik, kimia, dan terapeutik. Inkompatibilitas fisik terjadi ketika kombinasi obat menghasilkan perubahan yang terlihat secara fisik. Inkompatibilitas kimia adalah terjadinya degradasi obat secara kimiawi sehingga mengakibatkan berkurangnya efektivitas obat dan dapat menyebabkan toksisitas (Nagaraju dkk., 2015). Sementara itu, stabilitas adalah obat berada dalam karakteristik asli obat tersebut dalam jangka waktu tertentu., dimana stabilitas ini dipengaruhi oleh $\mathrm{pH}$, pelarut, suhu, cahaya, dan bahan wadah yang digunakan (Phillips dan Gorski, 2014).

Penelitian sebelumnya melaporkan bahwa terdapat kejadian inkompatibilitas pada $85 \%$ pasien anak dengan obat yang beresiko menyebabkan inkompatibilitas adalah diazepam, fenobarbital, fenitoin dan metronidazol (Leal dkk., 2016). Penelitian lain juga melaporkan bahwa kejadian inkompatibilitas pada pasien anak sebesar $3.4 \%$ pasangan obat, $86.3 \%$ pasangan obat kompatibel, dan $10.3 \%$ undocumented/unknown. Tidak ditemukan konsekuensi klinik dari kejadian inkompatibilitas obat dalam penelitian ini (Gikic dkk., 2000). Pemilihan pelarut yang tidak tepat juga dapat menurunkan stabilitas obat (Ong dan Subasyini, 2013).

Kejadian inkompatibilitas dan ketidakstabilan obat dapat menyebabkan kegagalan terapi dan membahayakan pasien terutama pada pasien anak dan neonatus. Selain itu kejadian ini dapat memperlama waktu rawat inap dan biaya pengobatan. Farmasis dapat berperan dalam menurunkan potensi kejadian inkompatibilitas pada pasien.

Penelitian terkait kompatibilitas dan stabilitas masih sangat terbatas. Oleh karena itu dilakukan penelitian ini dengan tujuan untuk mengetahui problem kompatibilitas dan stabilitas pencampuran sediaan intravena pada pasien rawat inap anak. 


\section{Metode Penelitian}

Alat

Alat yang digunakan dalam penelitian ini adalah rekam medis pasien rawat inap anak di PICU dan bangsal anak, lembar observasi pengumpul data yang berisikan identitas pasien dan pengobatan yang diberikan, buku standar Handbook of Injectable Drugs dan referensi lain seperti standar Rumah Sakit dan jurnal atau literatur lain.

\section{Tahapan Penelitian}

Penelitian dilakukan dengan pengambilan data dilakukan secara prospektif di RSUP Dr. Sardjito Yogyakarta di ruang rawat inap intensif anak (PICU) dan bangsal anak dari bulan November-Desember 2017.

Penelitian dilakukan dengan cara observasi pada shift pagi dan siang di jam kerja yaitu saat pemberian obat mulai pukul 07.0015.00. Pengambilan sampel dilakukan secara purposive sampling dimana pengambilan data dilakukan pada pasien yang memenuhi kriteria inklusi penelitian yaitu pasien rawat inap anak di PICU dan bangsal anak yang menggunakan minimal 1 jenis obat intravena dengan rekam medis lengkap.

Pengamatan dilakukan mulai dari penyiapan obat intravena sampai obat diberikan kepada pasien. Dilakukan pengamatan terhadap perubahan fisik yang mungkin terjadi selama penyiapan dan pemberian obat baik yang diberikan secara $y$ site maupun pencampuran/mixture.

\section{Analisa Data}

Kompatibilitas dilihat pada pasangan obat dengan obat, obat dengan pelarut, obat dengan infus, serta infus dengan infus. Sedangkan stabilitas dilihat dari rentang waktu setelah obat direkonstitusi sampai obat diberikan kepada pasien.

Kompatibilitas dan stabilitas akan dikaji menggunakan referensi standar yaitu Handbook of Injectable Drugs dan referensi lain seperti standar Rumah Sakit dan jurnal atau literatur lain. Data yang dikumpulkan akan dilakukan analisis secara deskriptif.

\section{Hasil dan Pembahasan}

Data yang dikumpulkan selama penelitian dilakukan adalah sebanyak 75 pasien yang didapatkan 34 pasien dari PICU dan 41 pasien dari bangsal anak. Jumlah pasien laki-laki dalam penelitian ini lebih besar dibandingkan jumlah pasien perempuan sebanyak 53.3\% $(n=40)$. Penelitian lain juga menemukan bahwa jumlah pasien laki-laki lebih banyak dibandingkan dengan pasien perempuan. Sebanyak $59.5 \%$ pasien di PICU adalah laki-laki (Leal dkk., 2016). Usia pasien didominasi oleh pasien yang berusia 1 bulan-2 tahun sebanyak $40.0 \%(n=30)$. Penelitian lain juga menemukan bahwa usia pasien di PICU didominasi oleh pasien dengan usia 0-2 tahun sebanyak 53.2\% (Leal dkk., 2016).

Rata-rata lama rawat inap pasien adalah $14.4 \pm 13.9$ hari. Jumlah pasien yang meninggal dunia selama penelitian berlangsung adalah 9.3\% $(n=7)$. Diagnosa masuk rumah sakit pasien sebagian besar dikarenakan penyakit infeksi $(24.0 \%)$, trauma dan penyebab lain dari faktor eksternal $(17.3 \%)$ dan penyakit sistem pernapasan seperti pneumonia (17.3\%). Penelitian sebelumnya melaporkan bahwa penyakit infeksi seperti pneumonia, infeksi sistem saraf pusat, dan sepsis merupakan penyakit infeksi yang memberikan efek fatal pada pasien anak, namun kasus kematian akibat penyakit infeksi dilaporkan mengalami penurunan dari tahun 1996 sampai dengan tahun 2004 di Finlandia (Lantto dkk., 2013).

Data penggunaan obat intravena dibandingkan dengan penggunaan obat yang diberikan melalui rute lain yaitu sebanyak $49.1 \%$ dengan rata-rata obat intravena 3.3 obat/pasien. Penggunaan obat intravena pada pasien anak dilaporkan tinggi pada pemberian intravena secara bolus sebanyak 57.8\% (Vazin, 2016). Jumlah pasien yang menggunakan kombinasi lebih dari 3 obat lebih banyak yaitu 46.7\%. Data karakteristik pasien dapat dilihat pada tabel berikut (Tabel 1).

Dalam penelitian ini diperoleh 266 kejadian pasangan obat intravena baik yang diberikan secara mixture maupun $y$-site yakni berturut-turut sebanyak $43.2 \%$ dan $56.8 \%$. Dari 266, sebanyak $73.7 \%$ pasangan obat kompatibel dan sebagian lagi sebanyak 26.3\% unknown/undocumented (Tabel 2). Hasil penelitian ini sama dengan penelitian sebelumnya, dimana jumlah pasangan obat yang kompatibel lebih besar dibandingkan dengan pasangan obat yang unknown/undocumented (Gikic dkk., 2000; Hanifah, 2016). Penelitian lainnya menemukan bahwa jumlah pasangan obat 
unknown/undocumented lebih banyak yaitu sebesar $38.59 \%$, pasangan obat inkompatibel sebesar 28.94\%, dan kompatibel sebesar $25.43 \%$ (Nagaraju dkk., 2015).

Tidak ditemukan kejadian inkompatibilitas dalam penelitian ini. Hal ini dikarenakan setiap pemberian obat intravena baik sebelum atau sesudah dilakukan flushing dengan menggunakan sterile water for injection (SWFI) atau $\mathrm{NaCl} 0.9 \%$ sebanyak $2-3 \mathrm{~mL}$. Flushing dapat mencegah terjadinya pengendapan pada pemberian kombinasi obat. Flushing sebanyak $1.5 \mathrm{ml}$ sebelum dan 2 $\mathrm{ml}$ sesudah dapat mencegah terjadinya kejadian inkompatibilitas (Hanifah, 2016).

Pencegahan terhadap inkompatibilitas perlu dilakukan karena kejadian inkompatibilitas dapat menyebabkan berbagai hal yang merugikan dan membahayakan pasien, bahkan dapat menyebabkan kematian. Penelitian melaporkan bahwa terjadi kasus kematian pada pasien neonatus akibat pemberian ceftriaxone bersamaan dengan larutan yang mengandung kalsium. Hal ini terjadi karena adanya pembentukan endapan yang dapat menyebabkan resiko terjadinya emboli (Bradley dkk., 2009). Penelitian lain melaporkan bahwa kejadian obat yang tidak diinginkan yang paling banyak terjadi adalah inkompatibilitas dan dilaporkan terjadi komplikasi akibat pemberian obat intravena seperti plebitis, infiltrasil atau ekstravasasi sebanyak $12.7 \%$ pada pasien (Vijayakumar dkk., 2014).

Tabel I. Data Karakteristik Pasien

\begin{tabular}{ll}
\hline $\begin{array}{l}\text { Karakteristik Demografi } \\
\text { dan Penyakit }\end{array}$ & $\mathbf{n ~ ( \% )}$ \\
\hline $\begin{array}{l}\text { Jenis kelamin } \\
\text { Laki-laki }\end{array}$ & $40(53.3 \%)$ \\
Wanita & $35(46.7 \%)$ \\
\hline Usia & $0(0 \%)$ \\
$0-1$ bulan & $30(40.0 \%)$ \\
1 bulan-2 tahun & $25(33.3 \%)$ \\
$2-12$ tahun & $15(26.7 \%)$ \\
$12-21$ tahun & $18(24.0 \%)$ \\
\hline $\begin{array}{l}\text { Penyakit } \\
\text { Penyakit infeksi dan parasit }\end{array}$ & $13(17.3 \%)$ \\
$\begin{array}{l}\text { Penyakit sistem pernapasan } \\
\text { Trauma dan penyebab lain }\end{array}$ & $13(17.3 \%)$ \\
$\begin{array}{l}\text { dari faktor eksternal } \\
\text { Penyakit sistem sirkulasi } \\
\text { Kongenital malformasi, } \\
\text { deformasi dan kromosom } \\
\text { abnormal }\end{array}$ & $7(9.3 \%)$ \\
\hline
\end{tabular}

\begin{tabular}{ll}
\hline Jumlah obat intravena & \\
$1-2$ obat & $40(53.3 \%)$ \\
3 atau lebih & $35(46.7 \%)$ \\
\hline
\end{tabular}

Permasalahan terkait stabilitas terdapat pada 3 pasangan obat yang digunakan di perawatan intensif anak pada 9 pasien anak yaitu dopamin dengan fentanil dan norepinefrin dengan dobutamin yang stabil selama 4 jam pada suhu $27^{\circ} \mathrm{C}$ yang diberikan secara $y$-site. Pasangan lainnya yaitu midazolam dan fentanil yang stabil selama 4 jam pada suhu $25^{\circ} \mathrm{C}$ (Tabel III). Belum terdapat penelitian lebih lanjut apabila digunakan lebih lama dari waktu tersebut. Sehingga perlu direkomendasikan penelitian lebih lanjut terkait stabilitas dari ketiga pasangan obat tersebut. Terutama untuk pasangan obat midazolam dan fentanil yang cukup banyak digunakan di perawatan intensif, dimana analgetik dan sedasi ini merupakan terapi yang penting untuk perawatan intensif (Brown dan Murray, 2001).

Tabel II. Data Kompatibilitas Obat

\begin{tabular}{ccccc}
\hline \multirow{2}{*}{$\begin{array}{c}\text { Peng } \\
\text { obatan }\end{array}$} & \multicolumn{3}{c}{ Kompatibilitas Obat } & Jumlah \\
\cline { 2 - 5 } Mixture & 112 & 0 & 3 & $\begin{array}{c}115 \\
(43.2 \%)\end{array}$ \\
\hline$Y$-site & 84 & 0 & 67 & $\begin{array}{c}151 \\
(56.8 \%)\end{array}$ \\
\hline Total & 196 & 0 & 69 & $\begin{array}{c}266 \\
(73.7 \%)\end{array}$ \\
\hline
\end{tabular}

Keterangan :

$\mathrm{C}$ : compatibile

I : incompatible

$\mathrm{U}$ : unknown

Tabel III. Data Stabilitas Obat

\begin{tabular}{clc}
\hline No & \multicolumn{1}{c}{ Kombinasi Obat } & Stabilitas \\
\hline 1. & Dopamin dan Fentanil & $4 \mathrm{hr}$ at $27^{\circ} \mathrm{C}$ a \\
\hline 2. & $\begin{array}{l}\text { Norepinephrin dan } \\
\text { Dobutamin }\end{array}$ & $4 \mathrm{hr}$ at $27^{\circ} \mathrm{C}$ a \\
\hline 3. & Midazolam dan Fentanil & $4 \mathrm{hr}$ at $25^{\circ} \mathrm{C}$ a \\
\hline Handbook of injectable drug $17^{\text {th }}$ edition
\end{tabular}

\section{Simpulan}

Tidak

ditemukan kejadian inkompatibilitas terhadap pasien rawat inap anak. Permasalahan stabilitas terjadi pada 3 pasangan obat apabila digunakan lebih dari waktu yang tertera pada literatur. 


\section{Ucapan Terima Kasih}

Terima kasih disampaikan kepada seluruh pihak yang telah membantu berjalannya penelitian ini.

\section{Daftar Pustaka}

Bradley, J.S., Wassel, R.T., Lee, L., dan Nambiar, S., 2009. Intravenous ceftriaxone and calcium in the neonate: assessing the risk for cardiopulmonary adverse events. Pediatrics, 123: e609-613.

Brown, D.R. dan Murray, M.J., 2001. Analgesia and Sedation in Critically Ill Patients. Zuckschwerdt.

Gikic, M., Di Paolo, E.R., Pannatier, A., dan Cotting, J., 2000. Evaluation of physicochemical incompatibilities during parenteral drug administration in a paediatric intensive care unit. Pharmacy world \& science: PWS, 22: 8891.

Hanifah, S., 2016. 'The Compatibility of Multiple Intravenous Drugs Administered Simultaneously', Charles Stunt University, Australia.

Kaushal, R., Bates, D.W., Landrigan, C., McKenna, K.J., Clapp, M.D., Federico, F., dkk., 2001. Medication errors and adverse drug events in pediatric inpatients. JAMA, 285: 2114-2120.

Lantto, M., Renko, M., dan Uhari, M., 2013. Changes in infectious disease mortality in children during the past three decades. The Pediatric Infectious Disease Journal, 32: e355-359.

Leal, K.D.B., Leopoldino, R.W.D., Martins, R.R., dan Veríssimo, L.M., 2016. Potential intravenous drug incompatibilities in a pediatric unit. Einstein (Sao Paulo, Brazil), 14: 185189.

Marsilio, N.R., da Silva, D., dan Bueno, D., 2016. Drug incompatibilities in the adult intensive care unit of a university hospital. Revista Brasileira de Terapia Intensiva, 28: 147-153.

Nagaraju, A., Deepak, A.S., Aruna, C., Swathi, K., dan Reddy, 2015. Assesment of intravenous admixtures incompatibilities and the incidence of intravenous drug administration errors. World Journal of Pharmacy and Pharmacentical Sciences, 4: 1227-1237.

Ong, W.M. dan Subasyini, S., 2013. Medication errors in intravenous drug preparation and administration. The Medical Journal of Malaysia, 68: 52-57.

Phillips, L.D. dan Gorski, L., 201AD. Manual of I.V. Therapeutics: Evidence-Based Practice for Infusion Therapy. F.A. Davis.

Vazin, A., 2016. Medication errors in Pediatric Intensive Care Unit: incidence, types and outcome. trends in pharmacentical sciences, 2:

Vijayakumar, A., Sharon, E.V., Teena, J., Nobil, S., dan Nazeer, I., 2014. A clinical study on drug-related problems associated with intravenous drug administration. Journal of Basic and Clinical Pharmacy, 5: 49-53. 